\title{
AVALIAÇÃO MICROBIOLÓGICA E FÍSICO-QUÍMICA DE PERNIS SUÍNOS TRATADOS COM ÁCIDOS ORGÂNICOS E/OU VAPOR NO CONTROLE DA CONTAMINAÇÃO SUPERFICIAL POR Salmonella Typhimurium
}

\author{
Andréa Rosa Machado ${ }^{1}$, Fábio Carvalho Gouveia ${ }^{2}$, Lídia Cristina Almeida Picinin ${ }^{2}$, Jalusa \\ DEON $\mathrm{KICH}^{3}$, MARISA RIBEIRO DE ITAPEMA CARDOSO ${ }^{4}$, SANDRA MARIA FERRAZ $^{2}$ \\ ${ }^{1}$ Professora Mestre, Instituto Federal do Rio Grande do Sul, Sertão, RS, Brasil. \\ andrearosamachado@hotmail.com \\ ${ }^{2}$ Professoras Doutoras da Universidade do Estado de Santa Catarina, Lages, SC. Brasil \\ ${ }^{3}$ Pesquisadora Doutora da Empresa Brasileira de Pesquisa Agropecuária, Centro Nacional de Pesquisa de Suínos \\ e Aves, Concórdia, SC, Brasil. \\ ${ }^{4}$ Professora Doutora da Universidade Federal do Rio Grande do Sul, Porto Alegre, RS, Brasil
}

Suínos portadores assintomáticos são o principal fator de risco para a contaminação de carcaças durante $o$ processamento industrial. Diferentes formas de prevenção e controle têm sido testadas no pós abate, dentre elas o uso de vapor e/ou ácidos orgânicos, que podem ser alternativas de baixo custo e alta eficiência. No presente estudo, testou-se o uso de solução de ácidos orgânicos e aplicação de vapor sob pressão, usados isoladamente ou em associação. Como poucas pesquisas trazem informações sobre o fato desses tratamentos promoverem ou não mudanças nas características físico-químicas da carne suína, o presente experimento se propôs também a avaliar as possíveis alterações físico-químicas de pernis submetidos a esses tratamentos. Porções de pernil foram contaminadas artificialmente com Salmonella Typhimurium DT 177 e, posteriormente, divididas em quatro tratamentos: imersão em solução fisiológica por 5 segundos (controle, T1); imersão em solução fisiológica acrescida de ácidos orgânicos 1000 ppm por 5 segundos (T2); aspersão de vapor sob pressão de 4 bar à temperatura de $140^{\circ} \mathrm{C}$ (T3); e T3 seguido por T2 (T4). Após o tratamento, uma área de $100 \mathrm{~cm}^{2}$ foi amostrada por meio de swab para quantificação da Salmonella residual pela técnica do número mais provável (NMP). Foram avaliados também o aspecto, coloração, consistência e odor, antes e após cada tratamento dos pernis, bem como análises físico-químicas visando à determinação do percentual de lipídeos, proteínas, pH, umidade e voláteis, também antes e após cada tratamento. Observou-se que o uso de vapor associado à imersão em solução de ácidos orgânicos a 1000 ppm apresentou melhor eficiência na redução das contaminações superficiais $(100 \%$ de frequência de redução), porém a melhor eficácia foi observada através da redução de 0,8 log base 10 do NMP na pele e $0,77 \log$ base 10 do NMP na musculatura através do uso de solução fisiológica (T1) e solução de ácidos orgânicos (T2), respectivamente. Os resultados obtidos revelaram que os tratamentos utilizados não interferiram nos atributos físico-químicos, como aspecto, cor, odor e consistência. $\mathrm{O}$ tratamento de vapor associado aos ácidos orgânicos diminuiu o $\mathrm{pH}$ e aumentou o teor de umidade e voláteis da carne, porém não descaracterizou a qualidade físico-química da carne suína, que permaneceu dentro de seus padrões ideais, apta ao consumo humano.

PALAVRAS-CHAVE: ácidos orgânicos; análises físico-químicas; pernil suíno; Salmonella sp.; vapor.

\section{MICROBIOLOGICAL AND PHYSICO-CHEMICAL EVALUATION OF PORK LEG TREATED WITH ORGANIC ACIDS AND/OR STEAM UNDER PRESSURE IN THE CONTROL OF SURFACE CONTAMINATION BY Salmonella Typhimurium}

\section{ABSTRACT}

Asymptomatic carrier pigs are the main risk factor for carcass contamination during the slaughter. Several postslaughter prevention programs have been tested, such as organic acids and steam under pressure. These alternatives show low cost and high efficiency. This study tested the use of organic acid solutions and steam, in isolated tests 
and its associations. This experiment also evaluated the physical-chemistry features of the pork. Forty pork legs were contaminated with Salmonella Typhimurium DT 177 and subsequently divided into 4 treatments: immersion in physiological solution for 5 seconds (control, T1); immersion in physiological solution with $1000 \mathrm{ppm}$ of organic acids for 5 seconds (T2); sprinkling of steam under pressure (4 bar) at $140^{\circ} \mathrm{C}$ (T3); and $\mathrm{T} 2$ after $\mathrm{T} 3$ (T4). An area of $100 \mathrm{~cm}^{2}$ was sampled through superficial swabs for Salmonella counts by Most Probable Number method (MPN). Aspect, color, consistency, smell, and levels of fat, protein, $\mathrm{pH}$, and moisture were also evaluated before and after each treatment. The use of steam associated to the immersion in organic acid solution showed better efficiency for reduction of superficial contamination (decreasing $100 \%$ of counts) but the better effectiveness was observed through the decreasing of 0.8 $\log$ of MPN at skin and $0.77 \log$ of MPN at muscle by using the physiological solution (T1) and the organic acid solution (T2), respectively. The steam treatment associated with the organic acid solutions (T4) decreased the $\mathrm{pH}$ and increased moisture of pork legs, although it did not mischaracterize the quality (within required parameters for human consumption). All the other treatments did not change physical-chemistry fefatures.

KEYWORDS: organic acids; physical-chemistry; pork leg; Salmonella sp.; steam.

\section{INTRODUÇÃO}

A carne suína é rica em nutrientes essenciais, sendo a proteína de origem animal mais consumida no mundo, contribuindo para a obtenção de uma alimentação balanceada. Possui sabor e maciez característicos, além de ser fonte de vitaminas e minerais (ODA, 2004).

No crescente mercado de produção suína, as agroindústrias procuram garantir aumento de produção aliado à lucratividade e à segurança alimentar do consumidor. Muitas ferramentas de gestão estão disponíveis para o controle de patógenos nos sistemas produtivos, como BPF (Boas Práticas de Fabricação) e APPCC (Análise dos Perigos e Pontos Críticos de Controle). Apesar disso, patógenos que causam toxinfecções alimentares, como Salmonella enterica, ainda podem ser isolados em produtos cárneos no Brasil (FERRAZ et al., 2004; SPRICIGO et al., 2008). A legislação brasileira determina a ausência de Salmonella sp. (ANVISA, 2001), porém os sistemas de produção de carnes suínas e derivados ainda enfrentam problemas de contaminação, tanto das carcaças em frigoríficos como dos suínos produzidos a campo. Essas informações vêm ao encontro das conclusões de FERRAZ et al. (2004) sobre a importância de suínos portadores de Salmonella abatidos e a contaminação de seu produto final. Várias pesquisas têm avaliado métodos de controle microbiológico em carnes (CONTE \& MARIN, 2003), porém com métodos diferenciados e resultados divergentes. Várias propostas vêm sendo estudadas para tratamento de carcaças suínas no pós-abate, como a utilização de ácidos orgânicos; o uso de água quente sob a forma de vapor e a associação do tratamento térmico com o químico.

Devido aos efeitos deletérios que a contaminação microbiana pode provocar na carne e considerando que os tratamentos que podem ser usados para descontaminar as carcaças não devem promover alterações em suas características físicoquímicas, o presente trabalho teve como objetivos: buscar uma alternativa para o controle superficial de Salmonella Typhimurium em pernis suínos artificialmente contaminados, avaliando o uso de ácidos orgânicos e vapor sob pressão, em tratamentos isolados e em associação e avaliar possíveis mudanças em suas características físicoquímicas.

\section{MATERIAL E MÉTODOS}

Este estudo foi dividido em duas etapas, sendo a primeira a avaliação microbiológica de pernis previamente contaminados por Salmonella Typhimurium fagotipo DT 177 e submetidos a quatro tratamentos, no Laboratório de Bacteriologia do Centro de Diagnóstico Microbiológico Animal (CEDIMA). A segunda etapa foi para a realização das análises físico-químicas dos pernis submetidos a três tratamentos, no Laboratório de Bromatologia, ambos do Centro de Ciências Agroveterinárias (CAV/UDESC), no período de junho a novembro de 2008.

Foram utilizados 40 pernis provenientes de abatedouro-frigorífico de suínos sob Inspeção Federal do Estado de Santa Catarina. Esses pernis foram resfriados e divididos em quatro partes, sendo que cada parte tinha peso médio de aproximadamente $3,5 \mathrm{~kg}$. O lote de suínos usado foi composto somente por fêmeas, com idade entre 160 e 180 dias.

Para a primeira etapa, os pernis previamente contaminados foram submetidos a quatro tratamentos diferentes:

- T1: imersão em solução fisiológica por 5 segundos; - T2: imersão em solução fisiológica ácida a 1.000 ppm (solução de ácidos orgânicos sendo o principal constituinte o ácido cítrico) por 5 segundos; 
- T3: aspersão de vapor sob pressão (4 BAR) a $140^{\circ} \mathrm{C}$, por 15 segundos;

- T4: associação do T3 seguido do tratamento T2.

Para a segunda etapa os pernis foram submetidos a três tratamentos diferentes:

- T 1.1: imersão dos pernis em solução composta por ácidos orgânicos (ácido ascórbico, ácido cítrico e ácido lático) a $1 \%$, diluídos em um litro de água destilada;

- T 2.1: aplicação de vapor por aspersão, gerado por equipamento próprio da marca Vaporex ${ }^{\circledR}$, com temperatura entre 120 a $140^{\circ} \mathrm{C}$, pressão de operação de 4 BAR, por tempo aproximado de 15 segundos;

- T 3.1: associação do T 2.1 seguido do T 1.1.

Para a realização da primeira etapa (avaliação microbiológica), foram utilizados 40 pernis suínos com pele e artificialmente contaminados por imersão em solução fisiológica estéril contendo $10^{3} \mathrm{UFC} / \mathrm{mL}$ de Salmonella Typhimurium - fagotipo DT177. Os pernis foram agrupados em quatro blocos para os devidos tratamentos e, para cada tratamento, foram realizadas 10 repetições. Após 15 minutos da realização da contaminação em solução com Salmonella Typhimurium, foram colhidas amostras da superfície de $100 \mathrm{~cm}^{2}$ de pele e de musculatura de cada pernil, com uso de suabes estéreis. Os pernis foram submetidos aos tratamentos específicos e novas amostras foram colhidas após 15 minutos da aplicação de cada tratamento, com o objetivo de avaliar a variação da quantidade de bactérias por superfície de área.

Para a quantificação de Salmonellas, os suabes foram inoculados em $100 \mathrm{~mL}$ de água peptonada tamponada estéril (APTE). Cada solução foi homogeneizada e a fase líquida repassada para tubos de APTE, segundo a técnica do Número Mais Provável (NMP) por $100 \mathrm{~mL}$ para série de três tubos, com inóculos de 10; 1 e 0,1mL (BRASIL, 2003). As amostras diluídas foram incubadas por 20 horas a $37^{\circ} \mathrm{C}$ e o isolamento da Salmonella sp. Foi realizado por meio do caldo Rappaport-Vassiliadis $\left(42^{\circ} \mathrm{C}\right.$ por 24 horas) e ágar XLD $\left(37^{\circ} \mathrm{C}\right.$ por 24 horas) (KICH et al., 2004). Os resultados foram expressos em $\mathrm{NMP} / 100 \mathrm{~cm}^{2}$ de superfície amostrada.

Para a realização da segunda etapa (análises físico-químicas), foram testados três tratamentos, nos quais se utilizaram 10 pernis por tratamento, com coleta em duplicata de amostras antes e após cada tratamento para comparação dos resultados obtidos.

Para execução das análises de aspecto, coloração, consistência, odor e físico-químicas, foram coletados aproximadamente 500 gramas de carne, antes de cada tratamento (servindo como grupo controle) e imediatamente após cada tratamento ( $\mathrm{T}$ 1.1, T 2.1, T 3.1). Essas porções de carne foram retiradas de várias regiões do pernil que não atingissem grandes vasos e nem tecidos adiposos, conforme BRASIL (1999). Após a coleta, essas porções de carne foram homogeneizadas em multiprocessador de alimentos.

Essas análises foram feitas sensorialmente, comparando a carne antes e após cada tratamento, para ver se algum dos tratamentos iria provocar alterações nessas características. Complementando essas análises, foi realizada a prova da cocção e, após a avaliação do odor, procedeu-se à fervura do material por mais 5 minutos para observação do aspecto da carne (BRASIL, 1999). As análises físico-químicas da carne, visando determinação do percentual de lipídios, proteína, $\mathrm{pH}$ e umidade foram realizadas conforme metodologia oficial descrita por BRASIL (1999).

Para a análise estatística das análises microbiológicas foram calculadas as frequências de amostras que reduziram o NMP de Salmonella sp. após o tratamento quando comparadas ao NMP inicial. Essas frequências foram comparadas através do teste exato de Fisher. Já para as análises físicoquímicas, os resultados foram avaliados através das comparações de médias pelo teste $\mathrm{t}$ para dados pareados, comparando-se o antes e o depois da aplicação de cada tratamento (SAS, 1999).

\section{RESULTADOS E DISCUSSÃO}

Para a primeira etapa (Avaliação Microbiológica), ao se analisarem os resultados obtidos no NMP na pele, observou-se que nos quatro casos houve efeito significativo $(p<0,05)$ do tratamento, sendo que o tratamento com ácido (T2) foi o que teve menor eficácia na frequência de redução da contaminação e o uso simultâneo de vapor mais ácido (T4) foi o mais eficaz (TABELA 1). A Figura 1 apresenta as médias dos NMPs e seus respectivos erros-padrão antes e após cada tratamento, em que as maiores reduções do NMP observadas foram com o uso de solução fisiológica (T1) $(0,8 \log$ base 10) e da solução ácida (T2) $(0,77$ $\log$ base 10) na pele e na musculatura, respectivamente. É importante observar que os tratamentos com solução fisiológica (T1) e vapor (T3) apresentaram resultados intermediários e não diferiram significativamente $(p>0,05)$ dos outros dois tratamentos.

A redução do NMP no tratamento com solução fisiológica (T1) pode ser atribuído ao fato de a água exercer efeito físico na retirada das células bacterianas de Salmonella Typhimurium presentes na superfície de carcaças suínas. Isso reitera o efeito da ação mecânica do líquido na retirada de células bacterianas superficialmente depositadas nos tecidos. 
Essa observação também foi realizada por CUTTER (1999), em estudo sobre contaminações experimentais superficiais por Salmonella Typhimurium em carcaças bovinas. Dessa forma, a ação mecânica dos líquidos durante a lavação de carcaças antes do resfriamento e armazenagem pode ser uma medida auxiliar no controle de Salmonella sp. depositada na superfície das carcaças.

Na musculatura, os tratamentos com solução fisiológica (T1) e vapor (T3) apenas reduziram a contagem em aproximadamente $40 \%$ das amostras, ao passo que os outros dois tratamentos (T2 e T4) foram mais efetivos, reduzindo a contagem em 100\% das repetições (TABELA 1).

Ao analisar os resultados do tratamento com solução fisiológica (T1), a frequência de redução da contagem foi maior na pele do que na musculatura. Isso pode ser atribuído ao fato de a superfície da pele ser mais uniforme e com menor quantidade de irregularidades para depósito de contaminantes. Esse argumento pode justificar também a menor influência do tratamento (T3) na musculatura do que na pele. Cabe também salientar que a irregularidade da superfície pode induzir maior retenção de líquidos e, consequentemente, menor homogeneização da distribuição de calor veiculado pelo vapor.

Apesar de ser possível inferir que o tratamento com solução ácida (T2) pode induzir a remoção mecânica das salmonelas da mesma forma que a solução fisiológica (T1), o resultado na musculatura apresentou frequência de redução da média de log de (NMP) de Salmonella Typhimurium maior do que na pele. Portanto, pode-se sugerir que a solução ácida utilizada em (T2) possui ação mais eficaz na musculatura do que na pele.

As ações isoladas dos tratamentos com vapor sob pressão (T3) e com solução ácida (T2) não foram satisfatórias neste estudo, sendo o baixo número de repetições um dos motivos para não se elucidarem os efeitos isolados de cada um desses tratamentos. Este estudo não permitiu definir os ácidos orgânicos como agentes químicos eficazes em tratamentos isolados no controle de Salmonella Typhimurium em contaminações superficiais de carcaças suínas. Dessa forma, um novo estudo com novo delineamento é sugerido para informações mais conclusivas.

Tabela 1. Porcentagens de amostras de pernil suíno que apresentaram redução na contagem do Número Mais Provável (NMP) de Salmonella após cada tratamento para descontaminação tanto na pele como na musculatura, retirando-se as amostras com contagens abaixo de 3NMP.

\begin{tabular}{lcc}
\hline Tratamento & Pele & Músculo \\
\hline Solução fisiológica (T1) & $87,5 \%(7 / 8)^{\mathrm{ab}}$ & $44,4 \%(4 / 9)^{\mathrm{b}}$ \\
Ácidos Orgânicos (T2) & $50,0 \%(4 / 8)^{\mathrm{b}}$ & $100,0 \%(10 / 10)^{\mathrm{a}}$ \\
Vapor (T3) & $75,0 \%(6 / 8)^{\mathrm{ab}}$ & $44,4 \%(4 / 9)^{\mathrm{b}}$ \\
Vapor+Ácido (T4) & $100,0 \%(10 / 10)^{\mathrm{a}}$ & $100,0 \%(9 / 9)^{\mathrm{a}}$ \\
\hline Teste Exato de Fisher (P) & 0,0486 & 0,0018
\end{tabular}

Porcentagens seguidas por letras diferentes nas colunas diferiram significativamente pelo teste exato de Fisher $(\mathrm{p}<0,05)$.
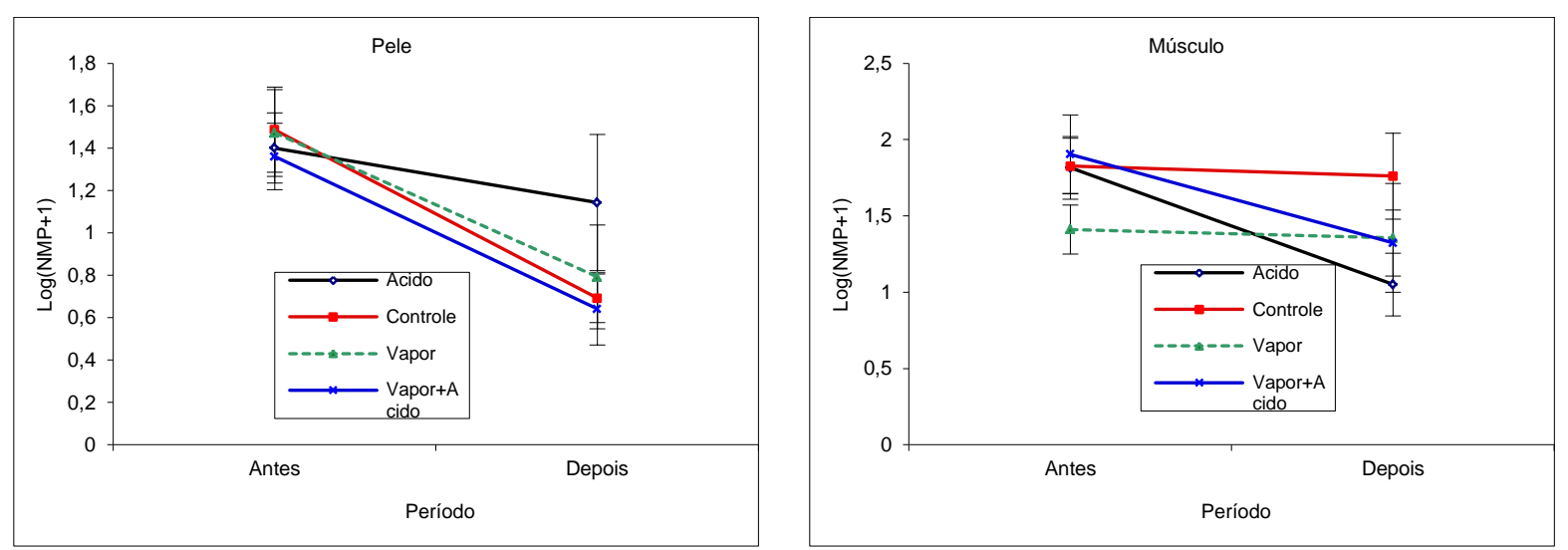

Figura 1. Médias e erros-padrão do Número Mais Provável (NMP de Salmonella sp. antes e após cada tratamento para descontaminação na pele e na musculatura dos pernis suínos. NMP transformado na escala logarítmica, retirando-se as amostras com contagens abaixo de 3 NMP. 
NETTEN et al. (1995) apontam melhores resultados para o controle microbiológico pela ação sinérgica química e física, fato observado também por GUERRERRO et al. (1995) por meio da associação de ácidos orgânicos e baixas temperaturas. Essas informações e a observação na redução do NMP em 100\% das repetições em (T4), tanto na pele como na musculatura, sugerem que a alta temperatura e a pressão de aspersão do vapor associado à ação química e mecânica da solução ácida justificam o melhor desempenho do tratamento (T4) no controle microbiológico de Salmonella Typhimurium na superfície de pernis suínos.

Para a segunda etapa (análises físicoquímicas), os resultados mostraram que os tratamentos utilizados não interferiram nos atributos aspecto, cor, odor e consistência dos pernis tratados. Isso confirma o que alguns autores encontraram em outras espécies (BELL et al., 1986; DUBAL et al., 2004), pois, como a aparência visual é o principal critério no qual o consumidor se baseia ao comprar produtos cárneos, é essencial que esta aparência seja mantida próxima dos níveis ótimos, esperados e desejáveis. É ainda necessário que se mantenha a estabilidade da cor da carne durante a distribuição, estocagem e comercialização. Nesse sentido, é importante que os tratamentos aplicados na carne que visam à redução da carga microbiana superficial não alterem a cor nem provoquem mudanças nas características organolépticas.

Conforme BRASIL (1999), as características desejáveis em relação ao aspecto da carne suína são: uniformidade, ausência de acúmulo sanguíneo, manchas e limo. A superfície de corte da carne suína de boa qualidade deve apresentar aparência marmórea, sem flacidez e exsudato. A carne suína deve possuir cor uniforme, entre rosada e avermelhada, apresentando uma pequena camada de gordura branca, com consistência firme e compacta e com odor suave, agradável e característico (sui generis).

Os resultados encontrados neste experimento confirmam o trabalho realizado por GOLDBACH \& ALBAN (2006), com carcaças suínas tratadas com água quente, no qual afirmaram que mudanças na cor da carne podem ocorrer, mas são transitórias e desaparecem após o resfriamento. GILL et al. (1999) testaram água quente em carcaças bovinas e verificaram que esse tratamento não causou prejuízos na aparência da carne. JAMES et al. (2000) avaliaram e testaram o uso de vapor e água quente em carcaças de cordeiro e os mesmos tratamentos não promoveram alterações na aparência da carne.

Nenhum dos três tratamentos propostos alterou a prova da cocção, seja no odor ou na consistência da carne. Essa é uma prova complementar que se fundamenta nas modificações de consistência, odores e sabor ocorridos nos alimentos em início de decomposição, realçadas pelo aquecimento da amostra. Os odores amoniacais, sulfídrico ou de ranço são facilmente identificados (BRASIL, 1999).

Conforme mostra a Tabela 2, os tratamentos T 1.1 e T 2.1 não alteraram as propriedades físicoquímicas da carne. VASCONCELOS et al. (2002), em trabalho realizado com carcaças ovinas tratadas com ácido acético, também não encontraram alterações no $\mathrm{pH}$ da carne após o tratamento. Entretanto, o tratamento $\mathrm{T} 3.1$ diminuiu o pH da carne e aumentou seu teor de umidade, porém isso não descaracterizou a carne e nem tornou-a imprópria ao consumo humano, podendo, inclusive, ser alterações transitórias como demonstram alguns trabalhos.

Observou-se neste trabalho que o tratamento $\mathrm{T} 3.1$ diminuiu o $\mathrm{pH}$, fato devido, provavelmente, ao aumento do poder de penetração do ácido pela aplicação conjunta do vapor, especialmente porque as análises foram realizadas imediatamente após a aplicação do tratamento. ÖZDEMIR et al. (2006) trataram carcaças bovinas com água quente seguida de ácido lático e observaram que o pH declinava logo após o tratamento; no entanto, após a carcaça ficar estocada em refrigeração a $4^{\circ} \mathrm{C}$ por 5 dias, o pH foi medido novamente, retornando ao normal. Conforme FIORUCCI et al (2002), o ácido lático provoca uma pequena e temporária redução no $\mathrm{pH}$ da carne, porém o pH volta ao normal de 48 a 72 horas após a aplicação.

$\mathrm{O}$ tratamento $\mathrm{T} 3.1$ aumentou o teor de umidade da carne, provavelmente devido à sua associação, alterando a capacidade de retenção de água (CRA) da carne. Conforme SILVA \& SOARES (2001), o uso de substâncias como ácidos orgânicos na carne pode alterar sua propriedade de retenção de água. Assim sendo, o calor do vapor pode ter aumentado a capacidade de absorção da solução de ácidos orgânicos (diminuindo o $\mathrm{pH}$ ), reduzindo, assim, a capacidade de retenção de água pela carne e aumentando seu teor de umidade. KOZEMPEL et al. (2003) relataram que o vapor é capaz de abrir os poros da superfície da carne, reforçando a tese de que ele aumentou a capacidade de absorção dos ácidos orgânicos. 
Tabela 2: Médias, desvios-padrão e nível descritivo de probabilidade do teste t para dados pareados para lipídios, proteína, umidade e $\mathrm{pH}$, com relação a diferentes tratamentos e composição físico-química do pernil suíno.

\begin{tabular}{lcc}
\hline & Período & Pr> t * \\
Tratamento & Antes & Depois \\
\cline { 2 - 3 } Lipídios & & \\
Vapor (T 2.1) & $1,91 \pm 0,063$ & $1,91 \pm 0,065$ \\
Vapor + Ácidos orgânicos (T 3.1) & $2,09 \pm 0,060$ & $2,09 \pm 0,057$ \\
Ácidos orgânicos (T 1.1) & $2,09 \pm 0,064$ & $2,10 \pm 0,061$ \\
Proteína & & \\
Vapor (T 2.1) & $22,18 \pm 0,159$ & $22,19 \pm 0,137$ \\
Vapor + Ácidos orgânicos (T 3.1) & $21,50 \pm 0,178$ & $21,50 \pm 0,113$ \\
Ácidos orgânicos (T 1.1) & $21,75 \pm 0,078$ & $21,74 \pm 0,195$ \\
Umidade & & \\
Vapor (T 2.1) & $75,87 \pm 0,135$ & $74,90 \pm 0,776$ \\
Vapor + Ácidos orgânicos (T 3.1) & $75,81 \pm 0,180$ & $76,28 \pm 0,187$ \\
Ácidos orgânicos (T 1.1) & $76,08 \pm 0,184$ & $75,88 \pm 0,335$ \\
pH & & \\
Vapor (T 3.1) & $6,11 \pm 0,088$ & $6,11 \pm 0,107$ \\
Vapor + Ácidos orgânicos (T 2.1) & $5,95 \pm 0,028$ & $5,88 \pm 0,034$ \\
Ácidos orgânicos (T 1.1) & $6,12 \pm 0,116$ & $6,11 \pm 0,131$ \\
\hline
\end{tabular}

* Nível descritivo de probabilidade do teste $\mathrm{t}(\mathrm{p}<0,05)$

\section{CONCLUSÕES}

O uso de vapor associado à imersão da carne em solução de ácidos orgânicos a 1000 ppm é uma ação eficiente no controle de contaminações superficiais de Salmonella Typhimurium em carne suína.

A imersão da carne suína em solução fisiológica exerce ação mecânica que resulta em boa eficácia na redução do NMP de Salmonella Typhimurium nas contaminações superficiais da pele presente na carne suína.

Os tratamentos propostos não alteram as características da carne como aspecto, cor, odor e consistência. Da mesma forma, quando aplicados isoladamente não alteraram as propriedades físicoquímicas da carne $(\mathrm{pH}$, lipídios, proteínas e umidade). $\mathrm{O}$ tratamento com vapor associado ao uso de ácidos orgânicos promoveu um leve declínio no $\mathrm{pH}$ e aumento no seu teor de umidade; entretanto, a carne permaneceu adequada ao consumo humano, pois suas características de cor, odor, sabor e consistência permaneceram inalteradas.

\section{AGRADECIMENTOS}

Ao professor Henrique Ribeiro Filho, do Laboratório de Bromatologia da Universidade do Estado de Santa Catarina e ao seu funcionário Maurílio, pelo auxílio na realização deste trabalho. Às acadêmicas Heloíse Peterle, Camila Pliéski e
Caroline Pisseti pelo auxílio na realização da parte prática do experimento e à Empresa Brasileira de Pesquisa Agropecuária - EMBRAPA - Suínos e Aves pela parceria no projeto, em especial ao pesquisador Arlei Coldebella pela análise estatística.

\section{REFERÊNCIAS}

ANVISA. Agência nacional de vigilância sanitária. Ministério da Saúde. Resolução RDC nº12 de 02 de janeiro de 2001.

BELL, M. F., MARSHALL, R. T., ANDERSON, M. E. Microbiological and sensory tests of beef treated with acetic and formic acids. Journal of Food Protection, v.49, n. 3, p. 207-210, 1986.

BRASIL. Ministério da Agricultura Pecuária e Abastecimento. Instrução Normativa $n^{\circ} 20$ de 21 de julho de 1999. Oficializa os métodos analíticos físico-químicos para controle de produtos cárneos e seus ingredientes - sal e salmoura. Diário Oficial da União, Brasília, 27 de agosto de $1999 . \quad$ Disponível em $<w w w . a g r i c u l t u r a . g o v . b r / a r q \_e d i t o r / f i l e / A n i a m a l / . . / l a b a$ lac.pdf> Acesso em 25 jul 2013.

CONTE, A. P. F; MARIN, J. M. Selection of 5fluorocytosine-resistant mutants from an Aspergillus niger citric acid-producing strain. Brazilian Journal of Microbiology, São Paulo, v. 34, n. 1, p. 1-4, 2003.

CUTTER, C.N. Combination spray washes of saponin with water or acetic acid to reduce aerobic and pathogenic bacteria on lean beef surfaces. Journal of Food Protection, v. 62, n. 3, p. 280-283, 1999. 
DUBAL, Z.B., PATURKAR, A. M., WASKAR, V. S., ZENDE, R. J., LATHA, C., RAWOOL, D. B., KADAM, M.M. Effect of food grade organic acids on inoculated $S$. aureus, L.monocytogenes, E. coli and S. Typhimurium in sheep/goat meat stored at refrigeration temperature. Meat Science, v. 66, n. 4, p. 817-821, 2004.

FERRAZ, S. M. ; SCHWARZ, P ; CANAL, C. W ; CARDOSO, M. R. I. Prevalência de suínos portadores de Salmonella sp. ao abate e contaminação de embutidos tipo frescal. Acta Scientiae Veterinariae, v. 32, n.2, p. 141147, 2004.

FIORUCCI, A. R., SOARES, M. H. F. B., CAVALHEIRO, E. T. G. Ácidos Orgânicos: dos primórdios da química experimental à sua presença em nosso cotidiano. Química Nova na Escola, $\mathrm{n}^{\circ} 15$, maio/2002; Disponível em <http://www. qnesc.sbq.org.br/online/qnesc15/v15a02.pdf>, acesso em 24, jul,2013.

GILL, C. O., BRYANT, J., BEDARD, D. The effects of hot water pasteurizing treatments on the appearances and microbiological conditions of beef carcass sides. Food Microbiology, v. 16, p. 281- 289, 1999.

GOLDBACH, S. G., ALBAN, L. A cost-benefit analysis of Salmonella-control strategies in Danish pork production. Preventive Veterinary Medicine, n 77, p 114, 2006.

GUERRERO, I., MENDIOLEA, R., PONCE, E., PRADO, A. Inoculation of Lactic Acid Bacteria on Meat Surfaces as a Means of Decontamination in Semitropical Conditions. Meat Science, v. 40, p. 397-411, 1995.

JAMES, C., THORNTON; J. A., KETTENRIGHAM, L., JAMES, S. J. Effect of steam condensation, hot water or chlorinated hot water immersion on bacterial numbers and quality of lamb carcasses. Journal of Food Engineering, v. 43, p. 219-225, 2000.

KICH， J. D.; BOROWSKY， L.; SILVA, V.; RAMENZONI, M.; TRIQUES, N.; CARDOSO, M. R. I. . Avaliação da atividade antibacteriana de desinfetantes comerciais frente a amostras de Salmonella Typhimurium isoladas de suínos. Acta Scientiae Veterinarie, v. 32, n.1, p. 33-39, 2004

KOZEMPEL, M.; GOLDBERG; CRAIG, J. C. Jr. The vacuum/steam/vacuum process. Food Technology, v. 57, n. 12 , p. $30-33,2003$

NETTEN, P.; MOSSEL, D.A.A.; VELD, H. Lactic acid decontamination of fresh pork carcasses:a pilot plant study, International Journal of Food Microbiology, v. 25, p. $1-9,1995$

ODA, E. I. Carnes PSE e DFD em aves e suínos: diferenças e semelhanças. Revista Nacional da Carne, n.325, p. 108-113, 2004.

ÖZDEMIR, H.; YILDIRIM, Y., KÜPLÜLÜ, O., KOLUMAN, A., GÖNCÜOGLU, M., INAT, G. Effects of lactic acid and hot water treatments on SalmonellaTyphimurium and Listeria monocytogenes on beef. Food Control, v. 17, p. 299-303, 2006.

SAS INSTITUTE (CARY NC). SAS User Guide: Statistical Analysis System, release 8.2, 1999; Disponível em

$<w w . u f r r j . b r / i n s t i t u t o s / i t / d e n g / . . / S A S \_o \_e s s e n c i a l \_d a \_l i n$ guagem.pdf>, acesso em 24 jul 2013.

SILVA, J. A; SOARES, L. F. Sanitização de Carcaças de Frango com Ácidos Orgânicos Comerciais e Suco de Limão. Revista TeC Carnes, v. 3, n. 1, p. 19-26, 2001.

SPRICIGO, D. A.; MATSUMOTO, S. R.; ESPÍNDOLA, M. L.; FERRAZ, S. M. Prevalência, quantificação e resistência a antimicrobianos de sorovares de Salmonella isolados de linguiiça frescal suína. Ciência e Tecnologia de Alimentos, v. 28, p. 1-7, 2008.

VASCONCELOS, E. C., ZAPATA, J. F. F., FIGUEIREDO, E. A., BRANCO, M. A. A. C., BORGES, A. S. A microbiota da carcaça e da carne ovina tratada com ácido acético, embalada a vácuo e maturada por 48 dias. Ciência e Tecnologia de Alimentos, Campinas, v.22, n. 3, 2002. 